\title{
Annual Maps of Forests in Australia from Analyses of Microwave and Optical Images with FAO Forest Definition
}

\author{
Yuanwei Qin $\left(\mathbb{D},{ }^{1}\right.$ Xiangming Xiao $\mathbb{D}^{1},{ }^{1}$ Jean-Pierre Wigneron $\left(\mathbb{D},{ }^{2}\right.$ Philippe Ciais $\left(\mathbb{D},{ }^{3}\right.$ \\ Josep G. Canadell, ${ }^{4}$ Martin Brandt, ${ }^{5}$ Xiaojun Li $\mathbb{D},{ }^{2}$ Lei Fan $\mathbb{D},{ }^{6}$ Xiaocui Wu, ${ }^{1}$ Hao Tang $\mathbb{D},{ }^{7}$ \\ Ralph Dubayah $\mathbb{D}^{8},{ }^{8}$ Russell Doughty $\mathbb{D}^{9},{ }^{9}$ Qing Chang, ${ }^{10}$ Sean Crowell, ${ }^{11}$ Bo Zheng, ${ }^{12}$ \\ Kevin Neal $\mathbb{C}^{1},{ }^{1}$ Jorge A. Celis $\mathbb{D}^{1},{ }^{1}$ and Berrien Moore III $^{11}$ \\ ${ }^{1}$ Department of Microbiology and Plant Biology, Center for Earth Observation and Modeling, University of Oklahoma, Norman, \\ OK 73019, USA \\ ${ }^{2}$ ISPA, UMR 1391, INRA Nouvelle-Aquitaine, Bordeaux Villenave d'Ornon, France \\ ${ }^{3}$ Laboratoire des Sciences du Climat et de l'Environnement, LSCE/IPSL, CEA-CNRS-UVSQ, Université Paris-Saclay, \\ 91191 Gif-sur-Yvette, France \\ ${ }^{4}$ CSIRO Oceans and Atmosphere, Canberra, ACT, Australia \\ ${ }^{5}$ Department of Geosciences and Natural Resource Management, University of Copenhagen, Copenhagen, Denmark \\ ${ }^{6}$ Chongqing Jinfo Mountain Karst Ecosystem National Observation and Research Station, School of Geographical Sciences, \\ Southwest University, Chongqing 400715, China \\ ${ }^{7}$ Department of Geography, National University of Singapore, 1 Arts Link, Kent Ridge, Singapore 117570 \\ ${ }^{8}$ Department of Geographical Sciences, University of Maryland, College Park, MD, USA \\ ${ }^{9}$ Division of Geological and Planetary Sciences, California Institute of Technology, Pasadena, CA 91125, USA \\ ${ }^{10} \mathrm{O}$ 'Neill School of Public and Environmental Affairs, Indiana University Bloomington, $702 \mathrm{~N}$ Walnut Grove Ave, Bloomington, \\ IN 47405, USA \\ ${ }^{11}$ College of Atmospheric and Geographic Sciences, University of Oklahoma, Norman, OK 73019, USA \\ ${ }^{12}$ Institute of Environment and Ecology, Tsinghua Shenzhen International Graduate School, Tsinghua University, \\ Shenzhen 518055, China
}

Correspondence should be addressed to Xiangming Xiao; xiangming.xiao@ou.edu and Jean-Pierre Wigneron; jean-pierre.wigneron@inra.fr

Received 10 April 2021; Accepted 2 August 2021; Published 23 August 2021

Copyright (C) 2021 Yuanwei Qin et al. Exclusive Licensee Aerospace Information Research Institute, Chinese Academy of Sciences. Distributed under a Creative Commons Attribution License (CC BY 4.0).

\begin{abstract}
The Australian governmental agencies reported a total of 149 million ha forest in the Food and Agriculture Organization of the United Nations (FAO) in 2010, ranking sixth in the world, which is based on a forest definition with tree height $>2$ meters. Here, we report a new forest cover data product that used the FAO forest definition (tree cover $>10 \%$ and tree height $>5$ meters at observation time or mature) and was derived from microwave (Phased Array type L-band Synthetic Aperture Radar, PALSAR) and optical (Moderate Resolution Imaging Spectroradiometer, MODIS) images and validated with very high spatial resolution images, Light Detection and Ranging (LiDAR) data from the Ice, Cloud, and land Elevation Satellite (ICESat), and in situ field survey sites. The new PALSAR/MODIS forest map estimates 32 million ha of forest in 2010 over Australia. PALSAR/MODIS forest map has an overall accuracy of $\sim 95 \%$ based on the reference data derived from visual interpretation of very high spatial resolution images for forest and nonforest cover types. Compared with the canopy height and canopy coverage data derived from ICESat LiDAR strips, PALSAR/MODIS forest map has $73 \%$ of forest pixels meeting the FAO forest definition, much higher than the other four widely used forest maps (ranging from 36\% to 52\%). PALSAR/MODIS forest map also has a reasonable spatial consistency with the forest map from the National Vegetation Information System. This new annual map of forests in Australia could support cross-country comparison when using data from the FAO Forest Resource Assessment Reports.
\end{abstract}




\section{Introduction}

The area, spatial distribution, and temporal dynamics of forests in Australia significantly influence biodiversity, carbon and water cycles, and climate [1-5]. Many efforts have been carried out to understand the spatial distribution and temporal changes of Australian forests. Australia's State of the Forests Report (SOFR), a five-year national report on the status of forests, has been generated since 1998 by the Australian Bureau of Agriculture and Resource Economics and Sciences (ABARES), Department of Agriculture, Water and the Environment [6]. The differences in forest area and spatial distribution among the SOFR reports cannot be considered as the actual forest change over years because different approaches have been used to generate the forest maps [6]. The National Vegetation Information System (NVIS) is a comprehensive data product providing information on the extent and distribution of various vegetation types in Australia and is collated from the NVIS data provided by individual states and territories [7]. A $250 \mathrm{~m}$ National Land Cover Dataset (NLCD) was produced by Geoscience Australia and the ABARES with the support of the NVIS, which is the first nationally consistent and thematically comprehensive land cover dataset for Australia [8]. Geoscience Laser Altimetry System (GLAS) observations onboard the Ice, Cloud, and land Elevation Satellite (ICESat) and the Phased Array L-band Synthetic Aperture Radar (PALSAR) data onboard the Advanced Land Observation Satellite (ALOS) were used to segment landscape and then were combined with NVIS to generate a structure-based classification of Australian vegetation [9].

According to the Global Forest Resources Assessment (FRA) reports, which were organized and released by the Food and Agriculture Organization (FAO) of the United Nations (UN), the Australian governmental agencies reported total forest areas of $1.49 \times 10^{6} \mathrm{~km}^{2}$ in FRA-2010, $1.24 \times 10^{6} \mathrm{~km}^{2}$ in FRA-2015 ( 16\% of Australian land area), and $1.34 \times 10^{6} \mathrm{~km}^{2}$ in FRA-2020 over Australia, which ranks Australia as the top 6th country in the world by forest area. Australian governmental agencies use a forest definition with tree canopy coverage of more than $20 \%$ and tree height of taller than $2 \mathrm{~m}$. However, according to the FAO/UN, forest is defined as over 0.5 ha land area with tree canopy coverage of more than $10 \%$ and tree height of taller than $5 \mathrm{~m}$ at the time of observations or at mature (young trees being expected to reach those thresholds). The FAO forest definition is accepted and used by most of the countries in the world. Australia is one of the few countries that use different forest definitions [10]. To date, to our knowledge, there are no annual forest maps in Australia that are based on the FAO forest definition. Therefore, there is a need to develop annual maps of forest cover with high accuracy in Australia, using the FAO forest definition, which can help assess forest resources across the globe, specifically across-country comparison in support of FAO FRA.

In this study, we generated annual maps of forests in Australia using the FAO forest definition by combining PALSAR imagery at a spatial resolution of $50 \mathrm{~m}$ and Moderate Resolution Imaging Spectroradiometer (MODIS) optical imagery at a spatial resolution of $250 \mathrm{~m}$ with a daily revisit cycle during
2007-2010, following the same forest mapping algorithms used in China, monsoon Asia, Brazilian Amazon, and South America [11-14]. We used large amounts of in situ georeferenced photos from the fields, forest field survey sites, very high spatial resolution images, and LiDAR-based canopy height and canopy coverage data to evaluate the annual forest maps. We compared the annual forest maps with other currently available forest area data products in Australia.

\section{Materials and Methods}

To generate an annual PALSAR/MODIS forest map and identify agreement and differences between the resultant PALSAR/MODIS forest map and other currently available forest maps in Australia, we used the following workflow (Figure 1). First, we generated the annual PALSAR/MODIS forest map in Australia. Second, we carried out the accuracy assessment for the PALSAR/MODIS forest map using multiple-source reference datasets. Third, we compared the forest area and spatial distribution between the PALSAR/MODIS forest map and five other forest maps in Australia.

2.1. Study Area. Australia, located between $10^{\circ} \mathrm{S}$ and $44^{\circ} \mathrm{S}$ and between $113^{\circ} \mathrm{E}$ and $154^{\circ} \mathrm{E}$, has an area of 7.6 million $\mathrm{km}^{2}$ and is the world's sixth largest country (Figure 2(a)). Australia has diverse climates across the country, including tropical monsoon climate in the north, oceanic and humid subtropical climate in the southeast, Mediterranean climate in the southwest, and arid and semiarid climate in the central area and west. Vegetation also has large spatial variation, for example, forest in the east and north of Australia, cropland in southeast and southwest of Australia, and grassland and shrubs in central and western Australia.

\subsection{PALSAR/MODIS-Based Annual Forest Maps}

2.2.1. PALSAR Data. We downloaded the PALSAR data at a spatial resolution of 50 meters from the Japan Aerospace Exploration Agency (JAXA). The PALSAR is an L-band (band wavelength of $\sim 23 \mathrm{~cm}$ ) active synthetic aperture radar. PALSAR fine beam dual (FBD) polarization mode has up to four observations at the same locations per year, mainly from June to October [15]. The best observation with minimum response to soil moisture was chosen to generate the PALSAR FBD data product. The PALSAR data available to the public include two polarizations: $\mathrm{HH}$ (horizontal transmitting, horizontal receiving) and $\mathrm{HV}$ (horizontal transmitting, vertical receiving). The digital numbers of PALSAR $\mathrm{HH}$ and $\mathrm{HV}$ were converted into gamma-naught backscattering coefficients in decibels [16]. We calculated the difference $(\mathrm{HH}-\mathrm{HV})$ and ratio $(\mathrm{HH} / \mathrm{HV})$ between $\mathrm{HH}$ and $\mathrm{HV}$. The false-color composite of PALSAR images shows the strong backscatter signals from forests (greenish color) in Australia (Figure 2(b)).

2.2.2. MODIS Data. We calculated the annual maximum Normalized Difference Vegetation Index (NDVImax) from the MOD13Q1 (Vegetation Indices 16-Day L3 Global $250 \mathrm{~m}$, Collection 5) product. MOD13Q1 product is a composite data with the best-quality observation in each 16-day 


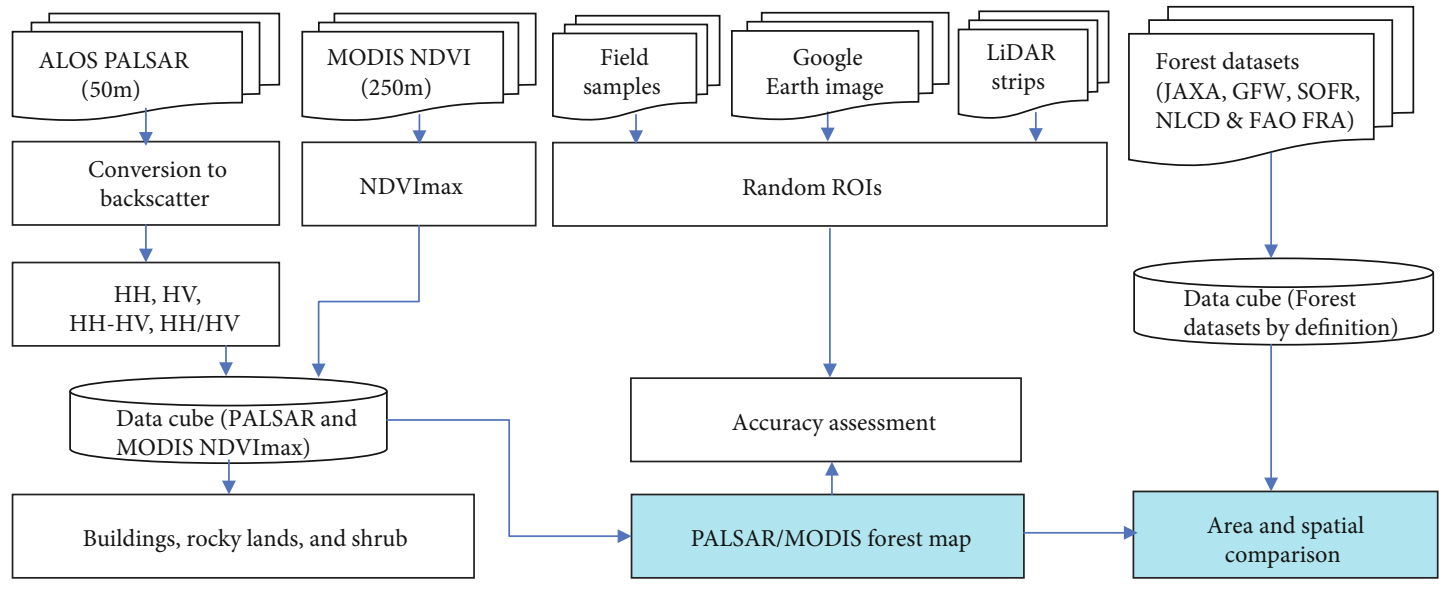

FIgURE 1: Workflow for the PALSAR/MODIS forest mapping tool.
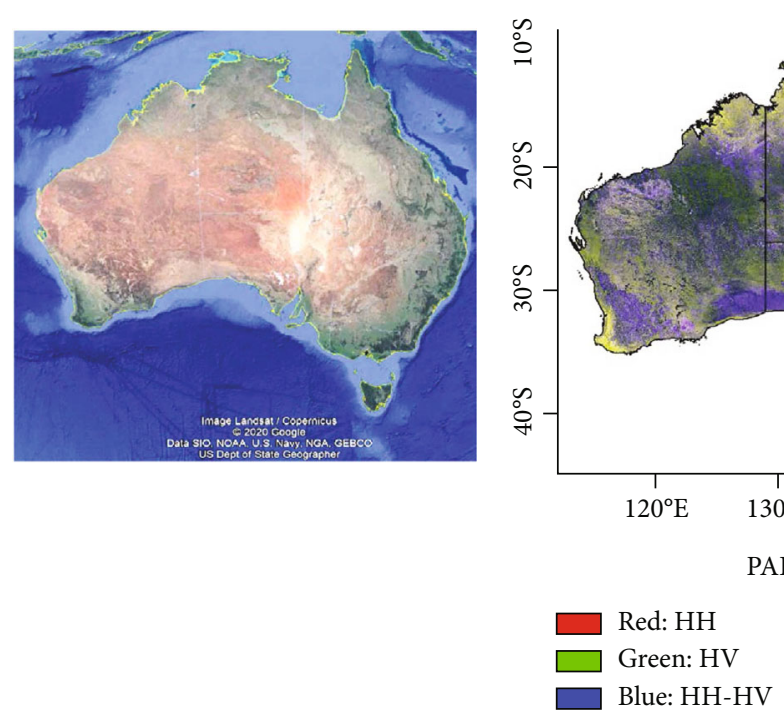

(a)

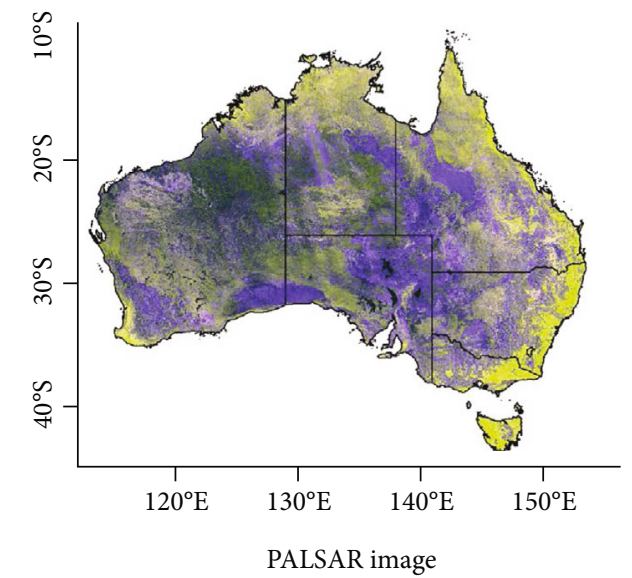

PALSAR image

Blue: HH-HV

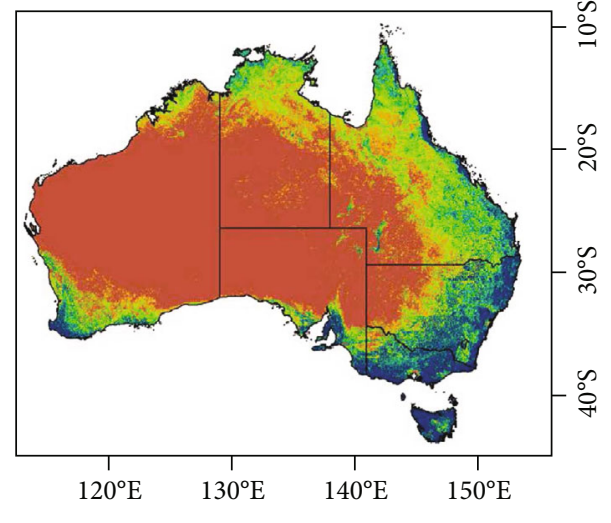

NDVImax

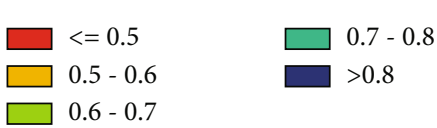

(c)

Figure 2: Spatial distribution of Google Earth image, PALSAR image, and the maximum Normalized Difference Vegetation Index (NDVImax) in Australia. (a) Google Earth image. (b) PALSAR false-color composite (red: HH, green: HV, and blue: HH-HV) in 2010. (c) The NDVImax image in 2010.

period from daily observations. We only used the goodquality observations each year to calculate the annual NDVImax in Australia (Figure 2(c)). The arid and semiarid areas covered by sparse vegetation have annual NDVImax less than 0.5 , and the other vegetated areas have annual NDVImax higher than 0.5 (Figure 2(c)).

2.2.3. PALSAR/MODIS Mapping Algorithm. The $50 \mathrm{~m}$ PALSAR/MODIS forest maps were generated by the integration of PALSAR FBD data and MOD13Q1 data for 2007-2010 (Figure 1). The L-band PALSAR can penetrate tree canopy and interact with tree trunks and branches, and thus, PALSAR data are sensitive to forest biomass and structure. The MOD13Q1 NDVI can reduce the commission errors caused by buildings, rocky land, and bare land, which have high HV backscatter coefficient values similar to forests and are often misclassified as forests when only PALSAR data were used [14]. In this study, we used the same PALSAR/MODIS mapping approach and thresholds used in South America [13], China [14], and monsoon Asia [11] to map forests in Australia.

2.3. Validation Data for PALSAR/MODIS Forest Map. Here, we assessed the accuracy of the PALSAR/MODIS forest map in 2010 using three independent reference datasets. First, we used visual image interpretation to collect a large number of reference land cover data based on very high spatial resolution images from Google Earth (Figure 3). Second, as the ICESat tree canopy height (meter) and tree canopy coverage (\%) datasets became available to the public recently [17], we used these LiDAR-based datasets to assess the PALSAR/MODIS forest map in Australia (Figures 4 and 5). Third, we used in situ forest survey sites across Australia (Figure 6). 


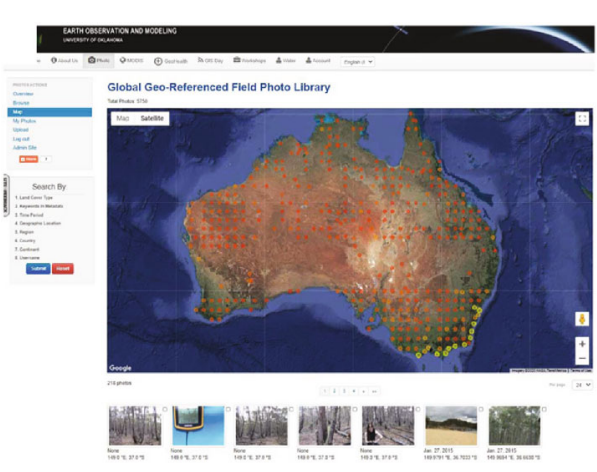

(a)

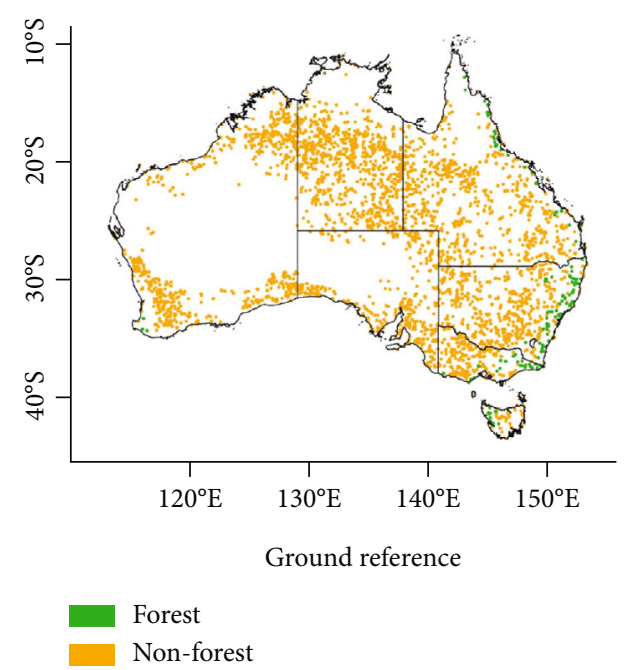

(b)

FIGURE 3: Spatial distributions of geo-referenced field photos and ground reference data for accuracy assessment of forest maps in Australia. (a) Geo-referenced field photos in Australia, which is freely available from the Global Geo-Referenced Field Photo Library, the University of Oklahoma (http://www.eomf.ou.edu/photos/). There is no field photo in Tasmania. (b) Ground reference data for forest and nonforest land cover types came from visual interpretation of very high spatial resolution images in Google Earth around 2010.

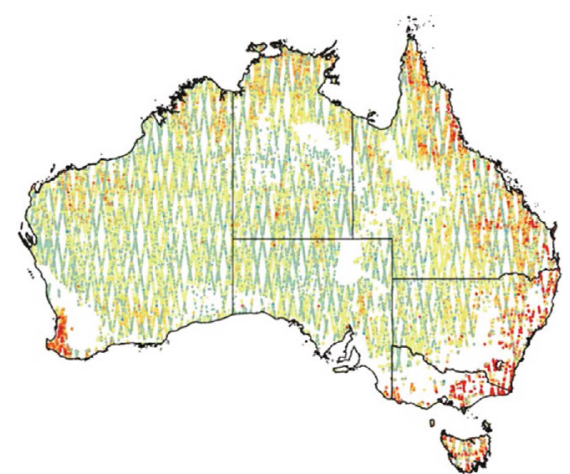

Canopy height $(\mathrm{m})$

$$
\begin{array}{ll}
<=2 & 10-15 \\
2-5 & 15-20 \\
5-10 & >20
\end{array}
$$

(a)

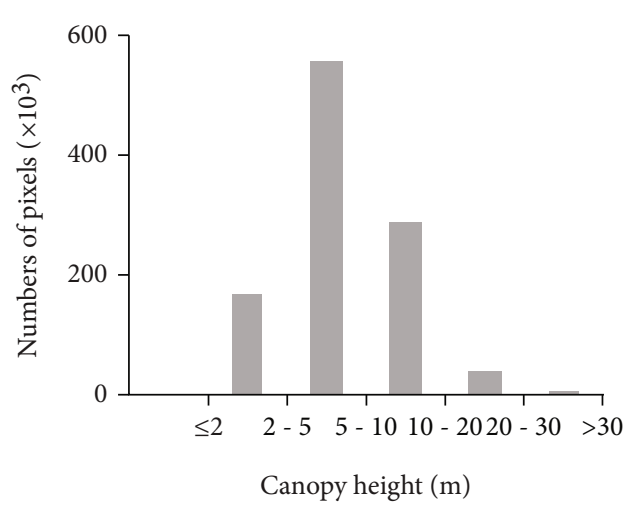

(b)

FIgure 4: Canopy height in Australia. (a) Spatial distribution of canopy height from the ICESat LiDAR strips. (b) Histogram of canopy height from ICESat data.

2.3.1. Very High Spatial Resolution Images. We assessed the accuracy of forest maps in Australia using a large number of ground reference samples visually interpreted from very high spatial resolution images around 2010 in Google Earth, with the support of geo-referenced field photos (Figure 3(a)). We randomly created 20 pixels at $500 \mathrm{~m}$ spatial resolution in each $1 \times 1$ degree (latitude and longitude) tile. Then, we overlaid these ground reference samples on the very high spatial resolution images in Google Earth and identified forest and nonforest pixels. If a $500 \mathrm{~m}$ pixel is covered by $90 \%$ or more forest cover, this pixel will be labeled as forest. If a $500 \mathrm{~m}$ pixel is covered by $90 \%$ or more nonforest cover, this pixel will be labeled as nonforest. Finally, we got 503 forest cover pixels and 2974 nonforest cover pixels at $500 \mathrm{~m}$ spatial resolution in Australia (Figure 3(b)).

\subsubsection{ICESat Canopy Height and Canopy Cover Percentage} Products. The canopy height and canopy cover percentage datasets are retrieved based on direct measurements of the three-dimensional canopy structure from the GLAS observations onboard NASA's ICESat [17]. The ICESat-GLAS observations recorded sample-based transects of canopy structure with a series of $\sim 65 \mathrm{~m}$ footprints illuminated by a LiDAR sensor. At each footprint, maximum canopy height and canopy 


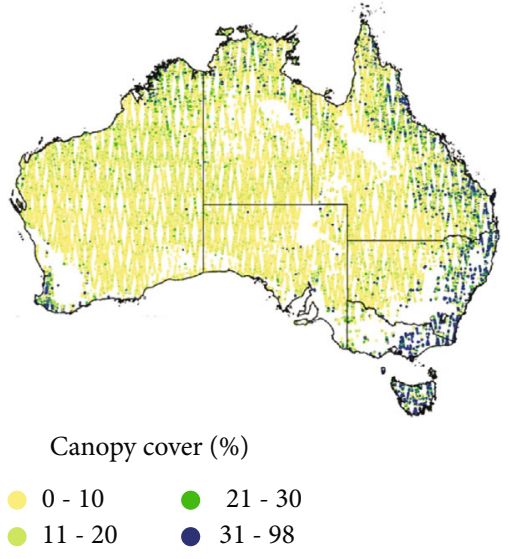

(a)

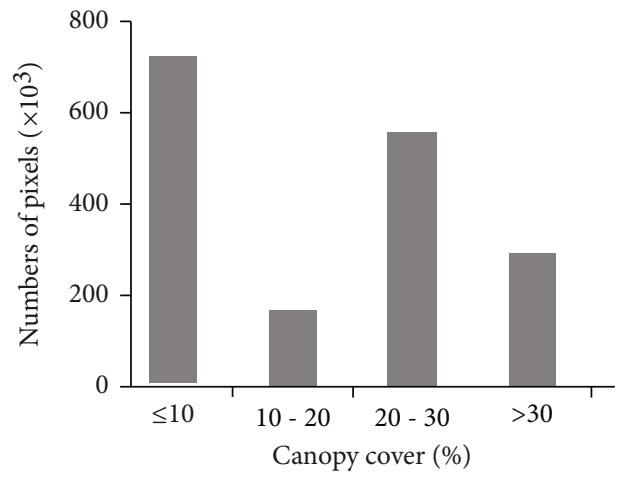

(b)

FIgure 5: Canopy cover (\%) in Australia. (a) Spatial distribution of canopy cover from the ICESat LiDAR strips. (b) Histogram of canopy cover.

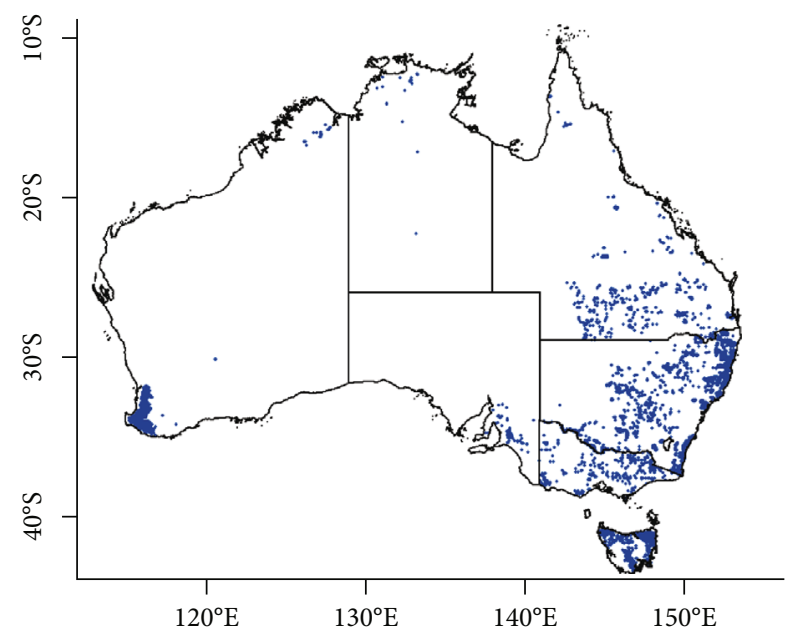

Figure 6: In situ forest survey sites from the Biomass Plot Library collected between 2001 and 2015 .

cover percentage are calculated from LiDAR waveform signals and screened for several confounding factors (e.g., cloud, noise, and topographic slope) [17]. The resulting ICESat canopy cover percentage showed almost no bias when compared with airborne LiDAR estimates and was sensitive to signal dynamics over dense forests even with canopy cover exceeding $80 \%$ [17]. The ICESat-based canopy height and canopy cover percentage estimates were able to better characterize footprint-level canopy conditions than the existing products derived from conventional optical remote sensing [17]. Yet, they cannot directly generate a wall-to-wall map of forest structure due to limited spatial samplings. Figures 4 and 5 show the spatial distribution of ICESat canopy height and canopy coverage in Australia.

2.3.3. Data from In Situ Tree and Shrub Biomass Survey Sites. We got the geographic location data of 9443 field sites from the Biomass Plot Library collected between 2001 and 2015, which is a national collation of tree and shrub inventory data, allometric model predictions of above- and belowground biomass in Australia (http://data.auscover.org.au/xwiki/bin/ view/Product+pages/Biomass+Plot+Library). About twenty organizations in Australia contributed to the Biomass Plot Library. Besides the biomass, each site contained a survey date, site name, site area, and geolocations. Each site covers an area of $0.05-1$ ha. We overlaid these field sites (Figure 6) over the PALSAR/MODIS forest map and assessed the accuracy of the PALSAR/MODIS forest map.

\subsection{Other Forest Data Products for Comparison}

2.4.1. Global Forest Watch (GFW) Forest Map. In the GFW dataset, tree cover is defined as any vegetation higher than $5 \mathrm{~m}$. The $30 \mathrm{~m}$ GFW tree cover map in 2010 was generated from a decision tree algorithm applied to multitemporal Landsat images acquired during the growing season around 2010 [18]. The accuracy assessment for the GFW forest map in 2010 remains unknown. We considered a pixel as forest when the GFW pixel has more than 10\% tree cover and tree height greater than $5 \mathrm{~m}$.

2.4.2. SOFR Forest Map. The SOFR-2013 and SOFR-2018 are from the ABARES [6]. The SOFR includes 44 indicators for the period from July 2006 to June 2011 (SOFR-2013) and from 2011-12 to 2015-16 (SOFR-2018). Forest is defined as canopy cover of more than $20 \%$ and tree height of larger than $2 \mathrm{~m}$. The forest area data in SOFR was derived using a "Multiple Lines of Evidence" approach at a spatial resolution of $100 \mathrm{~m}$, which integrates forest cover data provided by state and territory land management agencies with data sourced from a variety of remote sensing methods. The resulting National Forest Inventory dataset contains an updated, more rigorous, and robust understanding of Australia's total forest area, the geographic distribution of national forest types, and the geographic distribution of forests of different tenures.

2.4.3. JAXA Forest Map. The $50 \mathrm{~m}$ JAXA global forest map was produced by using PALSAR FBD mode data from June to September in 2010 [15]. Forest is defined as land with more than $10 \%$ tree cover and tree height greater than $5 \mathrm{~m}$. 


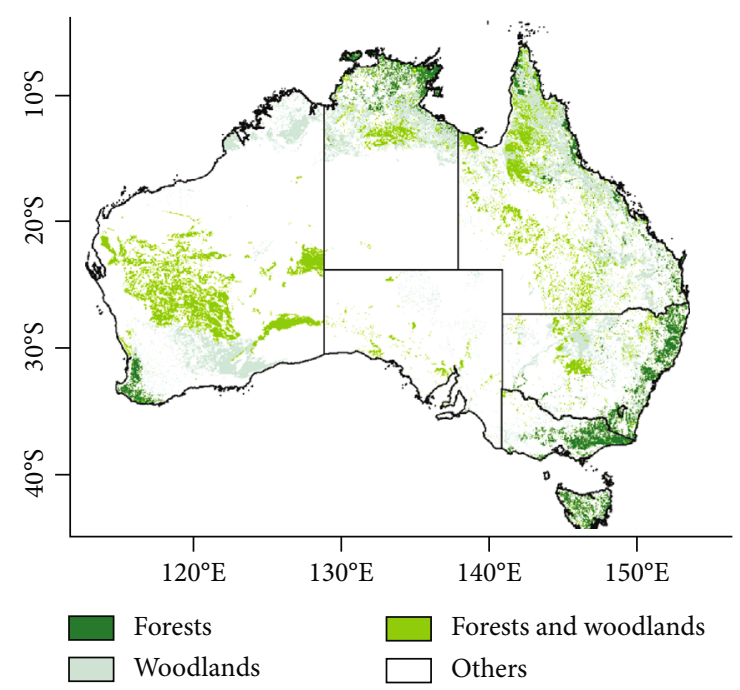

Figure 7: Spatial distribution of NVIS forest and woodland in Australia.

Data preprocessing activities include speckle reduction, orthorectification and slope correction, intensity equalization between neighboring strips, and median filter. Forest was identified by a decision tree algorithm and 15 regionspecific threshold values. Finally, the overall accuracy of the JAXA forest map was assessed at approximately 85\%, 91\%, and $95 \%$, using validation points from the Degree Confluence Projects, forest area statistics from the FAO Global Forest Resources Assessment, and Google Earth high spatial resolution images, respectively.

2.4.4. National Vegetation Information System (NVIS). The NVIS provides information on the extent and distribution of vegetation types in Australia [7]. The NVIS data are collated from the NVIS data provided by individual states and territories, which were generated by several decades of vegetation survey and mapping with a variety of survey methods and classification schemes. The NVIS map has a spatial resolution of 100 meters. Out of 33 major vegetation groups in NVIS, we include the following 11 major vegetation groups as forest and woodland (Figure 7): (1) rainforests and vine thickets, (2) eucalypt tall open forests, (3) eucalypt open forests, (4) eucalypt low open forests, (5) eucalypt woodlands, (6) acacia forests and woodlands, (7) Callitris forests and woodlands, (8) Casuarina forests and woodlands, (9) Melaleuca forests and woodlands, (10) Melaleuca forests and woodlands, and (30) unclassified forest.

2.4.5. National Land Cover Data (NLCD) Forest Map. The NLCD is the first nationally consistent and thematically comprehensive land cover reference for Australia, produced from the collaboration of Geoscience Australia and the ABARES [8]. The NLCD is based on analysis of 16-day $250 \mathrm{~m}$ enhanced vegetation index (EVI) composites from the MODIS/Terra Vegetation Indices 16-Day L3 Global $250 \mathrm{~m}$ SIN Grid (MOD13Q1) during 2000-2008. The time series EVI for each pixel with noise removal preprocessing was analyzed using an innovative technique that reduced each time series into 12 coefficients based on the statistical, phenologi$\mathrm{cal}$, and seasonal characteristics. These coefficients were then clustered using a support vector machine algorithm, and the resulting classes were labeled using national data supplied from catchment-scale land use mapping in 2009 and the National Vegetation Information System (NVIS). Extensive field validation sites were used to assess the accuracy of the NLCD land cover map [8]. The match between the 25,817 field validation sites and the NLCD was exact in $30 \%$ of cases, very similar in $35 \%$ of cases, moderately similar in $10 \%$ of cases, somewhat similar in $18 \%$ of cases, and completely mismatched in $7 \%$ of cases [8]. The NLCD defines tree as "Native and non-native woody plants more than 2 meters tall usually with a single stem or branches well above the base. Not always distinguishable from large shrubs."

2.4.6. FAO FRA Forest Area Statistics. FAO reports the world's forests every 5 to 10 years, mainly based on country reports and satellite images [19]. Forest is defined as land ( 0.5 ha or more) with more than $10 \%$ tree cover and tree height greater than 5 meters at maturity. The FAO FRA reports include about 90 variables, including the area, condition, uses, and values of forests. In this study, we used the FAO FRA forest area statistic for Australia in 2010, which is based on the Australian national forest reports that define forests with tree height larger than $2 \mathrm{~m}$ (the same as the NLCD and SOFR datasets).

\section{Results and Discussion}

3.1. Accuracy Assessment of Five Annual Forest Cover Maps. There are many satellite-based forest cover maps, and they are affected by (1) forest definitions, (2) satellite images (e.g., spatial resolution, image number, and quality), (3) training data (e.g., amount and quality), and (4) the mapping (classification) algorithms. We generated a new forest map in Australia in 2010 at a spatial resolution of $50 \mathrm{~m}$ by using both synthetic aperture radar (PALSAR) images and optical images (MODIS), as well as the FAO forest definition. Geographically, the PALSAR/MODIS forest map reveals the extent and spatial distribution of forests, and most of them were distributed in eastern Australia (Figure 8(a)).

In our previous publications, we evaluated the PALSAR/MODIS forest mapping tool and resulting annual forest maps for 2010 in monsoon Asia [11, 14] and South America $[12,13]$ with large amounts of ground reference data and very high spatial resolution images, and their overall accuracies are about $96 \%$. When we used the Global Land Cover Validation Reference Dataset (2 m spatial resolution) from the United States Geological Survey (USGS) with a forest definition of tree height greater than $5 \mathrm{~m}$ to validate the PALSAR/MODIS forest maps, we reported an overall accuracy of $\sim 90 \%$ in those PALSAR/MODIS forest maps $[12,13]$. In this study, based on the confusion matrix generated from very high spatial resolution images ( $>0.3$ million pixels), the PALSAR/MODIS, GFW, and JAXA forest maps showed a similar overall accuracy of $>96 \%$, but GFW and JAXA forest maps had relatively high commission errors $(\sim 15 \%$ and 


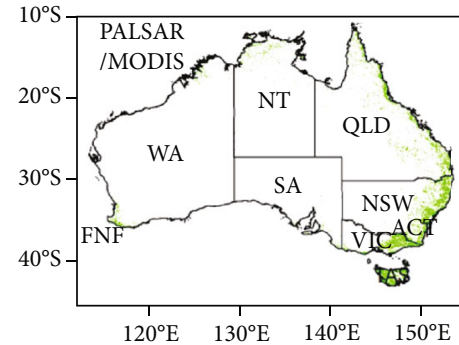

(a)

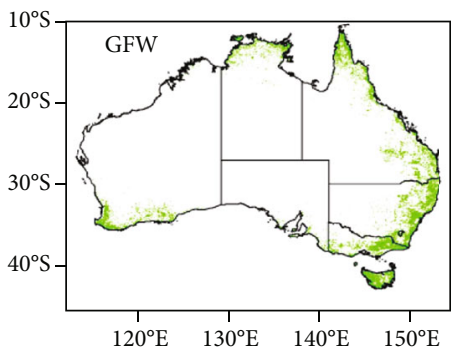

(b)

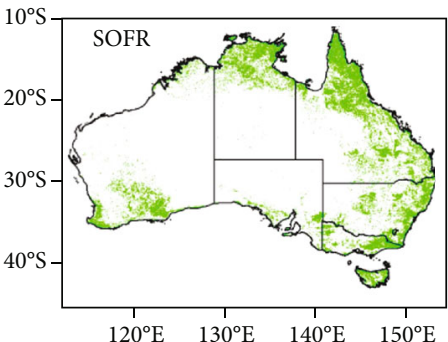

(c)

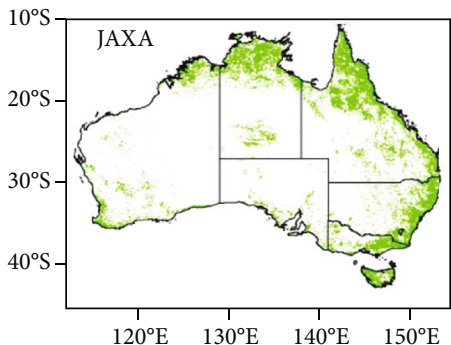

(d)

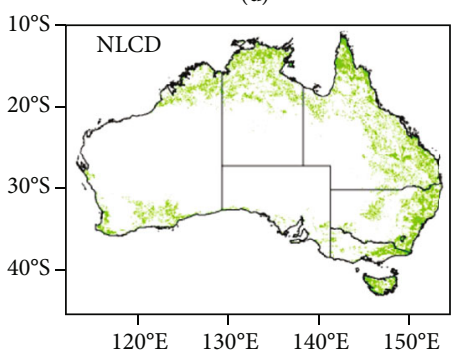

(e)

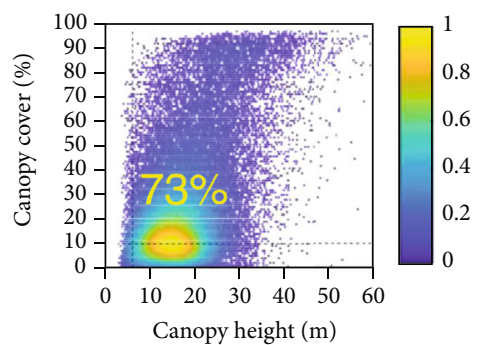

(f)

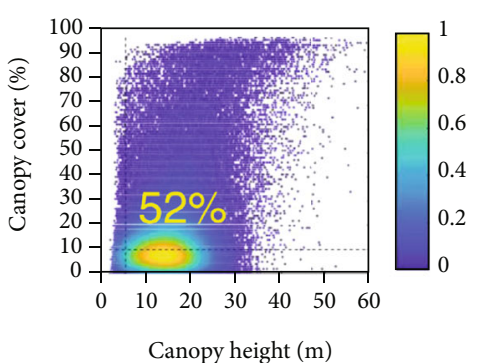

(g)

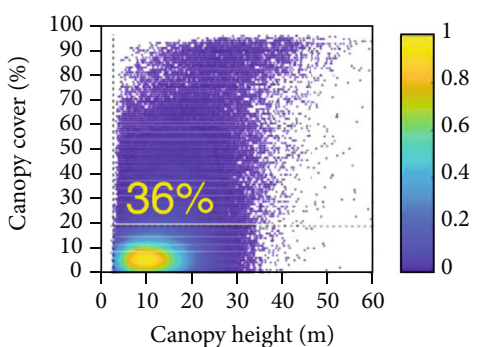

(h)

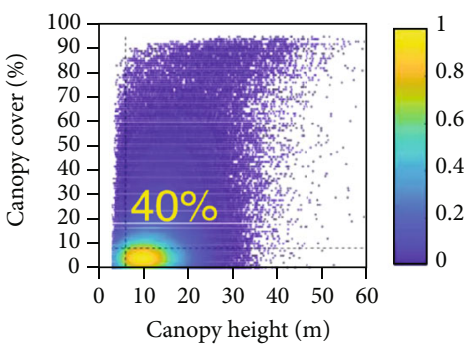

(i)

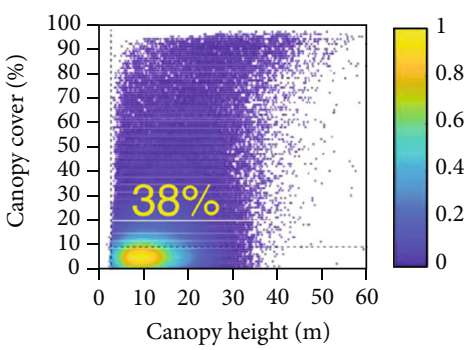

(j)

Figure 8: Spatial distribution of five forest cover maps in 2010 in Australia. (a) PALSAR/MODIS forest map at $50 \mathrm{~m}$ spatial resolution. (b) GFW forest map at $30 \mathrm{~m}$ spatial resolution. (c) SOFR forest map at $100 \mathrm{~m}$ spatial resolution. (d) JAXA forest map at $50 \mathrm{~m}$ spatial resolution. (e) NLCD forest map at $250 \mathrm{~m}$ spatial resolution. (f-j) Scatter plots of forest pixels in 2 dimensions of ICESat-based canopy height and canopy coverage for PALSAR/MODIS (f), GFW (g), JAXA (h), SOFR (i), and NLCD (j) forest maps. The numbers inside (f-j) indicate the percentages of forest pixels that meet the FAO forest definition. The color bars with ( $\mathrm{f}-\mathrm{j}$ ) are the density of forest pixels. The state abbreviations in (a): Western Australia (WA), Northern Territory (NT), South Australia (SA), Queensland (QLD), New South Wales (NSW), Australian Capital Territory (ACT), and Tasmania (TAS). 
TABLE 1: Confusion matrix for three forest cover maps in Australia in 2010, when using the reference data that were derived from visual interpretation of very high spatial resolution images from Google Earth.

\begin{tabular}{|c|c|c|c|c|c|c|}
\hline \multirow{2}{*}{ Forest maps } & \multirow{2}{*}{ Classification } & \multicolumn{2}{|c|}{ Reference } & \multirow{2}{*}{ Total number of pixels } & \multirow{2}{*}{ User accuracy (\%) } & \multirow{2}{*}{ Commission error (\%) } \\
\hline & & Forest & Nonforest & & & \\
\hline \multirow{5}{*}{ PALSAR/MODIS } & Forest & 13855 & 1034 & 14889 & 93.06 & 6.94 \\
\hline & Nonforest & 1049 & 293679 & 294728 & 99.64 & 0.36 \\
\hline & Total number of pixels & 14904 & 294713 & 309617 & & \\
\hline & Producer accuracy (\%) & 92.96 & 99.65 & & & \\
\hline & Omission error (\%) & 7.04 & 0.35 & \multicolumn{3}{|c|}{ Overall accuracy $=99.33 \%$} \\
\hline \multirow{5}{*}{ JAXA } & Forest & 14908 & 10989 & 25897 & 57.57 & 42.43 \\
\hline & Nonforest & 51 & 283451 & 283502 & 99.98 & 0.02 \\
\hline & Total number of pixels & 14959 & 294440 & 309399 & & \\
\hline & Producer accuracy (\%) & 99.66 & 96.27 & & & \\
\hline & Omission error (\%) & 0.34 & 4.73 & \multicolumn{3}{|c|}{ Overall accuracy $=96.43 \%$} \\
\hline \multirow{5}{*}{ GFW } & Forest & 37834 & 6648 & 44482 & 85.05 & 14.95 \\
\hline & Nonforest & 575 & 734076 & 734651 & 99.92 & 0.08 \\
\hline & Total number of pixels & 38409 & 740724 & 779133 & & \\
\hline & Producer accuracy (\%) & 98.50 & 99.10 & & & \\
\hline & Omission error (\%) & 1.50 & 0.90 & \multicolumn{3}{|c|}{ Overall accuracy $=99.07 \%$} \\
\hline
\end{tabular}

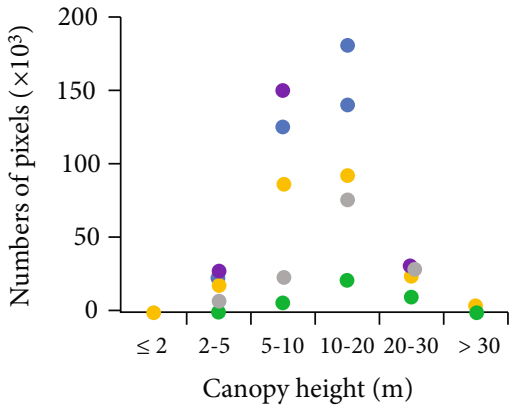

(a)

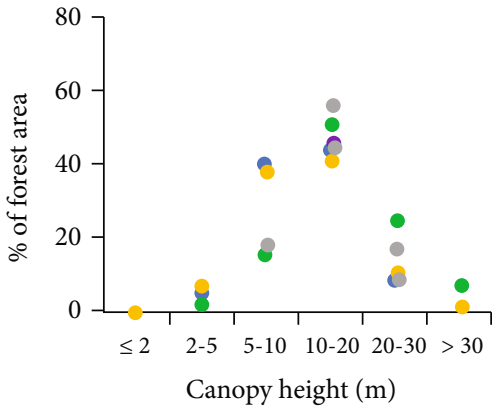

(b)

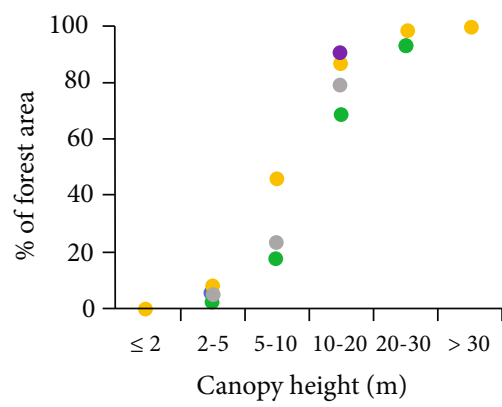

(c)

\footnotetext{
- PALSAR/MODIS • SOFR

GFW NLCD

- JAXA
}

FIGURE 9: Histograms of forest pixels across ICESat canopy height distribution for the five forest maps. (a) Numbers of forest pixels for different canopy height intervals. (b) Percentage of forest area for different canopy height intervals. (c) Accumulated percentage of forest pixels for different canopy height intervals.

$42 \%)$, indicating that they overestimated forest areas in Australia (Table 1).

We compared the PALSAR/MODIS forest map with other four forest cover maps in Australia in 2010 (Figure 6), including $30 \mathrm{~m}$ GFW forest map, $25 \mathrm{~m}$ JAXA forest map, the $100 \mathrm{~m}$ SOFR forest map, and the $250 \mathrm{~m}$ NLCDAustralia forest map. These four forest area data products were generated using either optical images (e.g., MODIS, Landsat) or synthetic aperture radar (PALSAR) images, and they have not been evaluated against a large amount of LiDAR data in terms of canopy height and canopy coverage. Although the ICESat canopy height and canopy coverage datasets (1.1 million footprints) have some uncertainties over steep terrain, they provide the viable data source for fieldscale estimates of canopy structure (e.g., canopy height, can- opy coverage) over the global land surface between 2003 and 2008 [17]. Over $99.9 \%$ of forest pixels from these forest maps have a canopy height of more than two meters. In terms of forest pixels with canopy height more than five meters, these five forest maps varied slightly, ranging from $97.8 \%$ for PALSAR/MODIS forest to $95.2 \%$ for GFW forest map, $93.7 \%$ for JAXA forest map, 93.2\% for SOFR forest map, and $92.3 \%$ for NLCD-Australia forest map (Figure 9). In terms of forest pixels with canopy coverage of more than $10 \%$, these five forest maps varied substantially, ranging from $74 \%$ for PALSAR/MODIS forest map to $53.8 \%$ for GFW, $42.5 \%$ for JAXA, 37.5\% for SOFR, and $40.7 \%$ for NLCD-Australia forest maps. Note that in terms of forest pixels with canopy coverage of more than 20\%, PALSAR/MODIS forest map $(50.9 \%)$ is still higher than GFW (28.3\%), JAXA $(21.9 \%)$, 


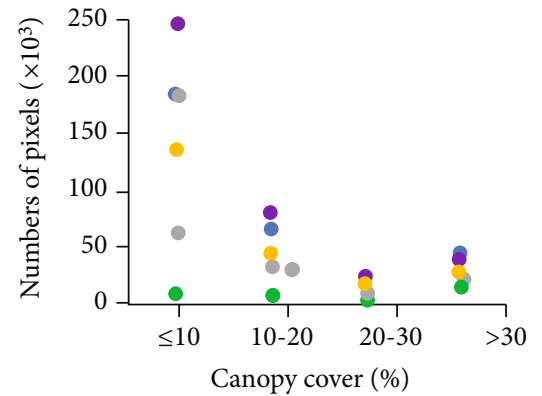

(a)

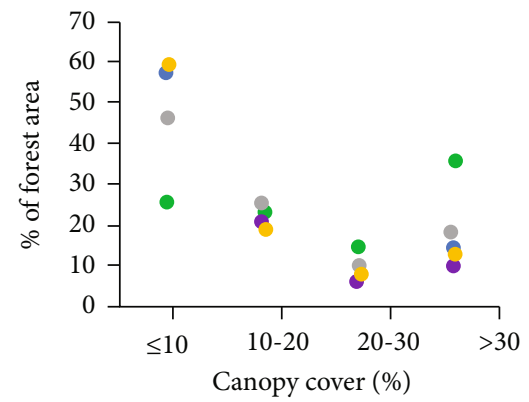

(b)

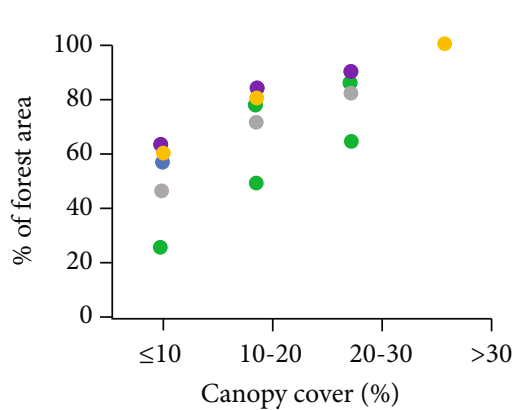

(c)

$$
\begin{array}{ll}
\text { - PALSAR/MODIS } & \text { SOFR } \\
\text { - GFW } & \text { NLCD } \\
\text { - JAXA } &
\end{array}
$$

FIgURE 10: Histograms of forest pixels across ICESat canopy coverage distribution for the five forest maps. (a) Numbers of forest pixels for different canopy cover intervals. (b) Percentage of forest area for different canopy cover intervals. (c) Accumulated percentage of forest pixels for different canopy coverage intervals.

SOFR (17.1\%), and NLCD-Australia (20.9\%) forest maps (Figure 10).

Overall, the results of this map accuracy assessment in the context of the ICESat canopy height and canopy coverage data show that $73 \%$ of the PALSAR/MODIS forest pixels meet the two criteria of the FAO forest definition, a much higher score than the GFW (52\%) or JAXA (40\%) forest data products (Figures $8(\mathrm{f})-8(\mathrm{j})$ ). Only $38 \%$ of the forest pixels in the NLCD-Australia and $36 \%$ of the forest pixels in the SOFR-2018 dataset meet both criteria used in the FAO forest definition. The PALSAR/MODIS forest map clearly identifies tall (5 $\mathrm{m}$ or higher) forests in Australia.

The PALSAR/MODIS forest map also showed reasonable consistency with the in situ site data from the tree and shrub biomass survey dataset. Out of 9943 field sites for tree and shrub biomass survey, which were done between 2001 and 2015 with different spatial resolutions and definitions from the PALSAR/MODIS forest maps, 5716 sites (60.5\%) were labeled as forest in the PALSAR/MODIS forest map, which is mainly distributed in eastern Australia. Most of the remaining field sites are distributed in the inland region of Australia and are not identified as forests in the PALSAR/MODIS forest map. Most of those field sites have small trees or shrubs.

\subsection{A Comparison of Forest Area Estimates at the National} Scale. At the national scale, GFW, JAXA, and FAO FRA had much different forest areas in 2010, ranging from 0.59 $\times 10^{6} \mathrm{~km}^{2}$ (GFW) to $1.49 \times 10^{6} \mathrm{~km}^{2}$ (FAO FRA-2010) in Australia $[6,8,15,18,19]$. NLCD-Australia $\left(1.18 \times 10^{6} \mathrm{~km}^{2}\right)$ had a similar forest area estimate with SOFR-2013 $\left(1.25 \times 10^{6} \mathrm{~km}^{2}\right)$ and SOFR-2018 $\left(1.34 \times 10^{6} \mathrm{~km}^{2}\right)$. The resulting PALSAR/MODIS forest map of Australia at $50 \mathrm{~m}$ spatial resolution estimates $0.32 \times 10^{6} \mathrm{~km}^{2}$ of forest in 2010 , which is $55 \%$ of the forest area estimate from the GFW dataset (30 m spatial resolution) [18], 24\% of the forest area estimate from the JAXA dataset (50 $\mathrm{m}$ spatial resolution) [15], and $22 \%$ of the forest area estimate from the FAO FRA country report in 2010 for Australia [19] (Figure 11).

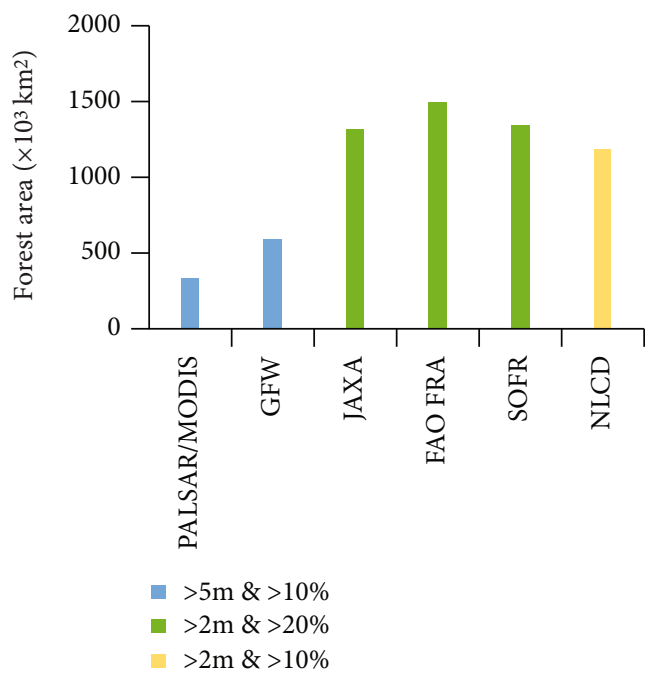

Figure 11: Forest areas in Australia from six forest data products in 2010 under different forest definitions. These forest products include the PALSAR/MODIS forest map at a spatial resolution of $50 \mathrm{~m}$ generated by this study, forest map at a spatial resolution of $25 \mathrm{~m}$ generated by the Japan Aerospace Exploration Agency (JAXA), forest map at a spatial resolution of $30 \mathrm{~m}$ generated by Global Forest Watch (GFW), FAO FRA forest area country report, Australia's State of the Forests Report (SOFR) forest map at a spatial resolution of $100 \mathrm{~m}$ for the five-year national report on the status of Australia's forests, and National Land Cover Data (NLCD)-Australia at a spatial resolution of $250 \mathrm{~m}$.

Our previous studies show that the PALSAR/MODIS forest area estimates in 2010 are close to the PALSAR-based forest areas estimated by JAXA forest maps in different regions, including China $\left(2.02 \times 10^{6} \mathrm{~km}^{2}\right.$ versus $\left.2.00 \times 10^{6} \mathrm{~km}^{2}\right)$ [14], monsoon Asia $\left(6.32 \times 10^{6} \mathrm{~km}^{2}\right.$ versus $\left.5.95 \times 10^{6} \mathrm{~km}^{2}\right)$ [11], South America $\left(8.63 \times 10^{6} \mathrm{~km}^{2}\right.$ versus $\left.8.19 \times 10^{6} \mathrm{~km}^{2}\right)$ [13], and Brazilian Amazon $\left(3.75 \times 10^{6} \mathrm{~km}^{2}\right.$ versus $3.69 \times 10^{6} \mathrm{k}$ $\mathrm{m}^{2}$ ) [12]. However, in this study, the PALSAR/MODIS forest area is only a quarter of Australia's JAXA forest area in 2010. According to Shimada et al. [15], they used 15 regional 
PALSAR HV threshold values to generate JAXA forest maps globally. Their HV threshold values in 14 regions are around -15 , similar to the criteria used to generate the PALSAR/MODIS forest maps, but they used a much lower HV threshold value (-20) to generate JAXA forest map in Australia, which is likely to be the primary cause for their very large estimates of forest area in Australia, which explains the large differences in forest area estimates between JAXA forest map and our PALSAR/MODIS forest map in Australia. Optical remote sensing images are not sensitive to tree height, and trees are easy to confuse with shrubs. The FAO FRA forest area estimates for Australia are mainly based on the Australia's SOFR, which is a five-year national report based on the forest definition with tree canopy coverage of more than $20 \%$ and tree height of taller than $2 \mathrm{~m} \mathrm{[10].} \mathrm{Therefore,} \mathrm{the}$ forest area estimates from FAO FRA are close to the SOFR reports. We also compared the spatial consistency between PALSAR/MODIS forest map and NVIS forest and woodland map (Figure 7). The results showed that $78.5 \%$ of the PALSAR/MODIS forest pixels were also identified as forest by the NVIS forest and woodland area data.

\section{Summary}

Forest area in Australia is relatively small compared to the extensive areas of woodland, savanna, grasslands, and desert, but these forests do provide unique habitats for biodiversity and essential ecosystem services to the region and the world, including their role as a carbon stock and sink. The PALSAR/MODIS forest map is accurate in area estimates of tall ( $\geq 5 \mathrm{~m}$ in height) forests in Australia, based on the accuracy assessment from very high spatial resolution images and LiDAR-based canopy height and canopy coverage footprints. It could serve as a new source of forest maps for crosscountry comparison of forests in the context of FAO Global Forest Resources Assessment.

\section{Data Availability}

All the data used in this study are publicly available. PALSAR data and JAXA forest map are available from JAXA (https:// www.eorc.jaxa.jp/ALOS/a/en/index_e.htm). MOD13Q1 is available from EARTHDATA (https://lpdaac.usgs.gov/ products/mod13q1v006/). The geo-referenced field photos are available from the Center for Earth Observation and Modeling, University of Oklahoma (https://www.ceom.ou .edu/). ICESat data is available from the Goddard Space Flight Center, National Aeronautics and Space Administration (NASA) (https://icesat.gsfc.nasa.gov/). The in-situ tree and shrub biomass survey data are available from the Biomass Plot Library (http://data.auscover.org.au/xwiki/bin/view/ Product+pages/Biomass+Plot+Library). GFW forest map is available from https://www.globalforestwatch.org/. SOFR forest map is available from ABARES, Australia (https:// www.agriculture.gov.au/abares/forestsaustralia/sofr). NVIS vegetation map is available from the Department of Agriculture, Water and the Environment, Australia (https:// www.environment.gov.au/land/native-vegetation/nationalvegetation-information-system). NLCD forest map is avail- able from the Geoscience Australia (https://www.ga.gov .au/scientific-topics/earth-obs/accessing-satellite-imagery/ landcover). FAO FRA forest area statistics are available from FAO (http://www.fao.org/documents/card/en/c/ca9825en/).

\section{Conflicts of Interest}

The authors declare no competing interests.

\section{Authors' Contributions}

X.X. and Y.Q. designed the overall study plan. Y.Q. and X.X. prepared the PALSAR/MODIS and evergreen forest maps. H.T. and R.D. prepared the ICESat canopy height and canopy cover dataset. Y.Q., X.X., X.W., R.D., Q.C., K.N., and J.C. carried our data processing and analysis. X.X., Y.Q., J.-P.W., P.C., J.C., B.M., X.L., L.F., and S.C. interpreted the results. Y.Q. and X.X. drafted the manuscript, and all coauthors contributed to the writing and revision of the manuscript.

\section{Acknowledgments}

This study is supported in part by research grants from the NASA Land-Cover and Land-Use Change program (NNX14AD78G) and the NASA Geostationary Carbon Cycle Observatory (GeoCarb) Mission (GeoCarb Contract \# 80LARC17C0001). We thank Sarah Xiao at the University of Oklahoma for editing the English language of this manuscript.

\section{References}

[1] D. M. J. S. Bowman, G. J. Williamson, O. F. Price, M. N. Ndalila, and R. A. Bradstock, "Australian forests, megafires and the risk of dwindling carbon stocks," Plant, Cell \& Environment, vol. 44, no. 2, pp. 347-355, 2021.

[2] B. G. Mackey, J. E. M. Watson, G. Hope, and S. Gilmore, "Climate change, biodiversity conservation, and the role of protected areas: an Australian perspective," Biodiversity, vol. 9, pp. 11-18, 2008.

[3] R. C. Deo, J. I. Syktus, C. A. McAlpine, P. J. Lawrence, H. A. McGowan, and S. R. Phinn, "Impact of historical land cover change on daily indices of climate extremes including droughts in eastern Australia," Geophysical Research Letters, vol. 36, article L08705, 2009.

[4] R. A. Vertessy, F. G. R. Watson, and S. K. O'Sullivan, "Factors determining relations between stand age and catchment water balance in mountain ash forests," Forest Ecology and Management, vol. 143, pp. 13-26, 2001.

[5] M. Ward, A. I. Tulloch, J. Q. Radford et al., "Impact of 20192020 mega-fires on Australian fauna habitat," Nature Ecology \& Evolution, vol. 4, pp. 1321-1326, 2020.

[6] Australian state and territory governments, Australia's State of the Forests Report 2018 Five-Yearly Report, Montreal Process Implementation Group for Australia and National Forest Inventory Steering Committee, Canberra, 2018.

[7] NVIS Technical Working Group, Australian Vegetation Attribute Manual: National Vegetation Information System, version 7.0, Department of the Environment and Energy, Canberra, 2017. 
[8] L. Lymburner, P. Tan, N. Mueller et al., The National Dynamic Land Cover Dataset - Technical Report, 2011.

[9] P. Scarth, J. Armston, R. Lucas, and P. Bunting, "A structural classification of Australian vegetation using ICESat/GLAS, ALOS PALSAR, and Landsat sensor data," Remote Sensing, vol. 11, no. 2, p. 147, 2019.

[10] FAO, Global Forest Resources Assessment, Country Report, Australia, FAO, Rome, 2014.

[11] Y. Qin, X. Xiao, J. Dong et al., "Mapping forests in monsoon Asia with ALOS PALSAR 50-m mosaic images and MODIS imagery in 2010," Scientific Reports, vol. 6, no. 1, 2016.

[12] Y. Qin, X. Xiao, J. Dong et al., "Improved estimates of forest cover and loss in the Brazilian Amazon in 2000-2017," Nature Sustainability, vol. 2, pp. 764-772, 2019.

[13] Y. W. Qin, X. M. Xiao, J. W. Dong et al., “Annual dynamics of forest areas in South America during 2007-2010 at 50m spatial resolution," Remote Sensing of Environment, vol. 201, pp. 73-87, 2017.

[14] Y. W. Qin, X. M. Xiao, J. W. Dong et al., "Forest cover maps of China in 2010 from multiple approaches and data sources: PALSAR, Landsat, MODIS, FRA, and NFI," ISPRS Journal of Photogrammetry and Remote Sensing, vol. 109, pp. 1-16, 2015.

[15] M. Shimada, T. Itoh, T. Motooka et al., "New global forest/non-forest maps from ALOS PALSAR data (2007-2010)," Remote Sensing of Environment, vol. 155, pp. 13-31, 2014.

[16] M. Shimada, O. Isoguchi, T. Tadono, and K. Isono, "PALSAR radiometric and geometric calibration," IEEE Transactions on Geoscience and Remote Sensing, vol. 47, no. 12, pp. 3915-3932, 2009.

[17] H. Tang, J. Armston, S. Hancock, S. Marselis, S. Goetz, and R. Dubayah, "Characterizing global forest canopy cover distribution using spaceborne lidar," Remote Sensing of Environment, vol. 231, p. 111262, 2019.

[18] M. C. Hansen, P. V. Potapov, R. Moore et al., "High-resolution global maps of 21st-century forest cover change," Science, vol. 342, no. 6160, pp. 850-853, 2013.

[19] Food and Agriculture Organization of the United Nations, Global Forest Resource Assessment (FRA) 2010, FAO, Rome, Italy, 2012. 